\title{
أطر معالجة الصحف الكويتية المطبوعة لقضايا المواطنة دراسة تحليلية مقارنة
}

\author{
نايف محمد حميان العراده* - (- ت
}

إثراف

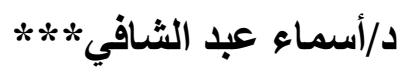

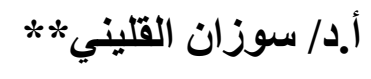

المستخلص

تحددت مشكلة الدراسة في الإجابة على تساؤل فحواه" ما أطر معالجة الصحف الكويتية المطبوعة لقضايا

المواطنة؟ وهدفت الدراسة إلى التعرف على أطر معالجة الصحف الكويتية المطبوعة لقضايا المواطنة. تم الاعتماد على نظرية تحليل الإطار الإعلامي في فهم واستيعاب الإطار الذى تناقش من خلاله الصحف

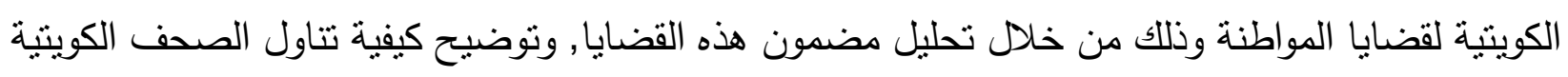
لقيم المواطنة .

تتنمي الدراسة إلى الدراسات الوصفية النحليلية في الدجال الإعلامي، واعتدت الدراسة على منهجين للإجابة

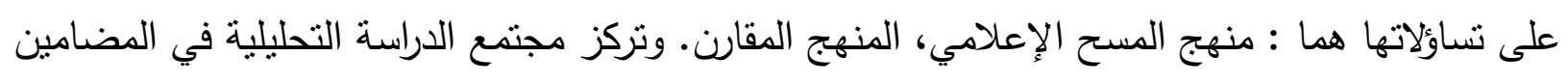

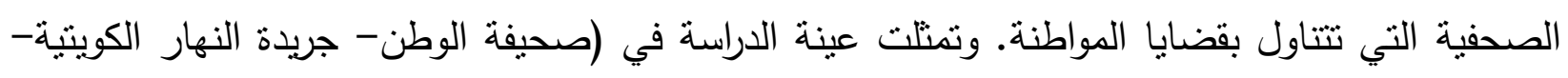
جريدة الراي الكويتية).

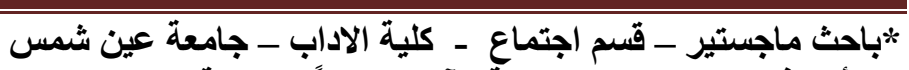

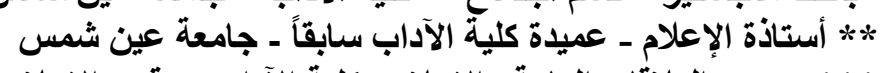
**: مدرس العلاقات العامة والإعلام ـ كلية الآداب - قسم الإعلام - جامعة عين شمس شئس 
- اهتمام الصحف الكويتية بقضايا المواطنة وكانت في مقدمها؛ إعلاء سيادة الدولة داخليا وخارجيا ، التأكيد على الحقوق والواجبات للفرد والمجتمع، التأكيد على الخصوصية والهوية الذاتية، التأكيد على قيم التسامح، التأكيد على المساواة.

- تنوعت الأطر الصحفية المنبعة في عرض قضايا المواطنة في صحف الدراسة وتمنلت في ؛ الإخبار ، التتاقثية. والنقد والثقويم، الاقتراحات والحلول،المقال. - تتوعت مصادر تغطية قضايا المواطنة في صحف الدراسة ما بين؛ الصحف المحلية والأجنبية، المندوب الصحفي، المراسل، الكتاب ، الانترنت.

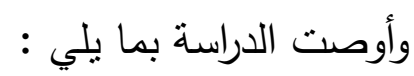
1- زيادة الاهتمام بتتوع قضايا المواطنة منل؛ إبراز أهمية التاريخ الوطني، التأكيد على الخصوصية الثقافية

$$
\text { دون تعصب أو انغلاق. }
$$

2- زيادة الاهتمام بالتقارير الرسمية كمصدر لقضايا المواطنة في صحف الدراسة. 3- زيادة الاهنمام بالمقالات والتحقيقات الصحفية التي تساعد على إبراز قضايا المواطنة.

$$
\text { الكلمات المفتاحية: المعالجة الصحفية - الصحف الكويتية - المواطنة }
$$

\section{تمهيد:}

لما كانت المواطنة تعني في مفهومها العام إحساس الإنسان بالانتساب إلى المجموعة وتقاسم شعورها، وتؤدي إلى تمسك الإنسان بعاداته وتقاليده ، كما تصل بالمواطن إلى التفاعل في أوسع معانيه مع الوطن ومع المواطنين، فهي إذا علاقة الفرد" بالوطن "من حيث هو" الأرض "المساحة الجغرافية والتاريخية والاجتماعية والسياسية، لذلك فإن المواطنة والروح الوطنية هي المحرك الحقيقي للحياة الاجتماعية، وتلك الروح الوطنية تتضمن مجموعة القيم التي تحدد علاقة الفرد بمجتمعه، وتصل به إلى الالتزام بالعقد الاجتماعي الذي يربط بين المواطنين المنساوبين في الحقوق والواجبات. 
تعد المواطنة عنصراً أساسيا من عناصر البناء الاجتماعي والسياسي في المجتمعات المعاصرة. فهي تعني الانتماء إلى مجتمع واحد يضمه بشكل عام رابط اجتماعي وسياسي وثقافي موحد في دولة معينة. يكون للمواطن فيه حقوق يجب أن تقدم إليه ويحمل في نفس الوقت مجموعة من المسؤوليات الاجتماعية التي يلزم عليه تأديتها. لذلك تعرف بأنها العضوية الكاملة والمتساوية في المجتمع بما ينرتب عليها من حقوق وواجبات. وتتهض المواطنة علي مجموعة من القيم تتمثل بصفة عامة في المساواة، العدل، الحرية، الديمقراطية، المشاركة والانتماء، تمثل هذه القيم القاسم المشترك بين مختلف المجتمعات، وقد يختلف تطبيقها من مجتمع لأخر. وترتبط المواطنة في المجتمع المصري بمجموعة من القيم ذات الصلة المباشرة بالواقع المجتمي

$$
\text { والسياسي المصري في الوقت الحالي. }
$$

أولاً: مشكلة الدراسة:

تمنل المواطنة أهمية باعتبارها حلقة الوصل الاجتماعية والقانونية بين الأفراد والمجتمع، كما أنها تتضمن عدد من القضايا والمسئوليات والواجبات، والمواطنة بمفهومها الواسع تعني الصلة بين الفرد والدولة التي يقيم فيها بشكل ثابت، ويرتبط بها جغرافيًا وتاريخيًا وثقافيًا .ويعد ازدياد الثعور بالمواطنة من التوجهات المدنية الأساسية، التي من أهم مؤشراتها الموقف من احترام القانون والنظام العام، والموقف من ضمان الحريات الفردية واحترام حقوق الإنسان، والتسامح وقبول الآخر وحرية التعبير وغيرها من المؤشرات التي تمثل القيم الأساسية للمواطنة، مهما اختلفت المنطلقات الفكرية والمرجعيات الفلسفية لهذا المجتمع أو ذاك. وأوصت دراسة الجبوري(2019) بضرورة اهتمام وسائل الإعلام والمؤسسات التربوية والدينية بقيم المواطنة كونها صمام للأمن المجتمي. وأكدت دراسة ريايعة(2019) على أهمية وسائل الإعلام في تعزيز القيم الوطنية لاى المواطنين

وتتحدد مشكلة الدراسة في الإجابة على تساؤل فحواه" ما أطر معالجة الصحف الكوينية المطبوعة لقضايا 
تهدف الدراسة إلى التعرف على أطر معالجة الصحف الكويتية المطبوعة لقضايا المواطنة. ويتفرع منه عدة أهداف هى:

1) التعرف على الفنون الصحفية المستخدمة في عرض قضايا المواطنة ومساحتها في صحف الدراسة.

2) التعرف على أولويات الاهنمام بقضايا قضايا المواطنة على مستوى صحف الدراسة. 3) رصد الأطر الصحفية المتبعة في عرض قضايا المواطنة في صحف الدراسة. 4) تحديد مصادر قضايا المواطنة في صحف الدراسة. 5) التعرف على مواقع نشر قضايا المواطنة على مستوى كل صحيفة. ثالثًا : تساؤلات الدراسة: تحاول الدراسة الإجابة على تساؤل رئيس فحواه: ما أطر معالجة الصحف الكويتية المطبوعة لقضايا

$$
\text { والمواطنة؟ }
$$

1) ما الفنون الصحفية المستخدمة في عرض قضايا المواطنة ومساحتها في صحف الدراسة؟ 2) ما أولويات الاهتمام بقضايا قضايا المواطنة على مستوى صحف الدراسة؟ بإب 3) ماهى الأطر الصحفية المتبعة في عرض قضايا المواطنة في صحف الدراسة؟ 4) ما مصادر قضايا المواطنة في صحف الدراسة؛ 5) هل تختلف مواقع نشر قضايا المواطنة باختلاف الصحيفة؟ رابعاً: أهمية الدراسة: تأتي هذه الدراسة في الوقت الذي اخذت تخرج بعض الكتابات التي تدق ناقوس الخطر من مخاطر تأثثر الإعلام على قيم وتوجهات الثباب، الأمر الذي عكس الصورة الذهنية لديهم تجاه قضايا المواطنة ، 
وكذللك ندرة الدراسات التي تتاولت هذا الموضوع بشكل مباشر في الكويت على - حد علم الباحث - وتكمن أهمية الدراسة أيضا في الاتي: -

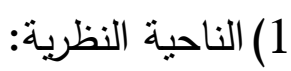
- الوقوف على أساليب تتاول الصحف المطبوعة الكويتية لقضايا المواطنة . - إثراء الدراسات المتعلقة بتتاول الصحف لقضايا المواطنة، بما يساهم في تحقيق التراكم المعرفي والبحثي.

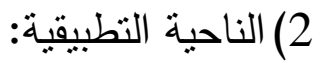
- إمكانية اقتراح بعض الحلول المناسبة للتصدي لسلبيات تتاول الصحف المطبوعة لقضايا المواطنة. - إمكانية تقديم رؤية شاملة تساهم في تعزيز أطر معالجة الصحف المطبوعة لقضايا المواطنة. خامساً: مفاهيم الاراسة: : (1) (1) المعالجة الصحفية

ويقصد بها الأسلوب الذى تتاولت به صحف الدراسة لقضايا المواطنة بالثرح والتفسير وتقديم الحقائق وعرض وجهات النظر المختلفة لمعالجـة هذه القضـــايـا وذلك من خلال الفنون التحريريـة كالخبر والمقال والتحقيق والحديث والكاريكاتير ....... وغيرها. (2) (2) مفهوم المواطنة: كما أن المواطنة تعني منظومة من الحقوق الأساسية أهمها الحق في الحياة والمساواة, والملكية الخاصة, والتعليم, والرعاية الصحية, والعمل والضمان الاجتماعي, والتفكير والعقيدة, إضافة إلى الانتخاب والتمثيل النيابي وتكوين النقابات والجمعيات والعدالة وتثاول المعلومات والتتقل(198-(ynn Dobson.2002.pp). تعرف " قيم المواطنة تعني مجموعة الأخلاقيات والعادات والسلوكيات التي يتثر بها الفرد من خلال التفاعل مع المواقف والخبرات، ويكون لها التأثير على أفكاره ومعتقداته، ويتحدد بها سلوكه لبناء رؤية صحيحة حول الحقوق والواجبات التي يتضمنها انتماؤه وولاءه لهذا الوطن"( الغامدي، 2010، ص24) 
يمكن تعريف قيم المواطنة على أنها " مجموعة المعايير والأحكام والمعتقدات التي تعمل كموجهات للسلوك، وضوابط للتفكير الناجم عن التفاعل بين الإنسان والأرض وما ينشأ عن هذا التفاعل من الالتزام بالحقوق والواجبات في شتى مناحي الحياة ( السياسية والاقتصادية والاجتماعية والقانونية والثقافية )، وما يتضمنه ذلك من قيم الولاء والانتماء والثشهادة والتضحية وترجمة ذلك إلى مواقف سلوكية ومهارات أدائية وصولا إلى تكوين المواطن الصالح." ( الكندري ، 2011)

فعلى الصعيد المعاصر أصبح يتضمن مفهوم المواطنة جانبين؛ جانب تقليدي وجانب افتراضي، الأول تمثل المواطنة فيه علاقة قانونية بين الإنسان ودولته القومية، فهي الوضع الذي يكون فيه المرء متمتعا بحقوقه وواجباته كمواطن في المجال المدني والسياسي والاجتماعي والاقتصادي والثقافي(طه ، عبد الحكيم، 2013،

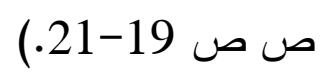

ويمكن وضع تعريف إجرائي للمواطنة في هذه الدراسة الآتي: الحق لكل مواطن بالعمل والعيش المشترك في إطار التآخي والتعاون دون تمييز في الحقوق الاجتماعية والاقتصادية والسياسية والدينية، دون تمييز ديني أو عرقي أو سياسي أو قبلي.

سادساً: الاراسات السابقة: لما كان البحث العلمي تراكمي، يمنل عرض الدراسات السابقة أهمية حيث تساعد على معرفة الأبعاد التي تمت دراستها، وكيفية دراستها، حتى يبدأ الباحث من حيث انتهى الآخرون. ويتم عرض الدراسات وفقا لتسلسها الزمني فيما يلي: 1 (2019) سميرة لغويل(م) يتتاول هذا البحث قيم المواطنة ويهدف إلى إبرازها وتأكيد دورها وفاعليتها في الحفاظ على مكونات المجتمع الجزائري، لأنها من المفاهيم الأساسية التي تعمل على تعزيز التلاحم المجتمي في عصرنا الحالي. وقد اعتمد هذا البحث على المنهج الوصفي المناسب لطبيعة الموضوع والذي يستتد أساسا على الدراسات الوثائقية. وقد 
تأكد لنا من خلال النتائج المتوصل إليها أن لقيم المواطنة دورا كبيرا في تطور المجتمعات وأن ترسيخها يتحقق من خلال توعية الأفراد وتعريفهم بحقوقهم وواجباتهم في المجتمع، فضلا عن دورها في استقرار النسق المجتمعي.

2) عبد العزيز خلف خليل الجبوري(2019) •

تتتاول هذه الدراسة قيم المواطنة في الصحافة الإمارتية من خلال تحليل مضمون مقالات كتاب الرأي في جريدة الاتحاد، وسعت هذه الدراسة إلى معرفة دور الصحافة في تتاول موضوع مهم وحيوي يتعلق بقيم المواطنة وأثرها على السلم والأمن المجتعي، وهي أول دراسة تحليلية لقيم المواطنة لجريدة إماراتية، من خلال تتاول كتاب الرأي فيها، واستتدنا في دراستتا إلى دراسات سابقة تعلمنا من خلالها توظيف المعلومات والأفكار التي تضمنتها بما يخدم البحث، وشملت هذه الدراسة الأسس المنهجية للبحث وإجراء تحليل المضمون وفق الاستمارة التي أعدت لهذا الغرض، وتم اعتماد الأولويات في إبراز قيم المواطنة حسب أهميتها ووفق جداول تم ترتيبها لهذا الغرض، وأوصت الدراسة بضرورة اهتمام وسائل الإعلام والمؤسسات التربوية والدينية بقيم المواطنة كونها صمام للأمن المجتمعي. 3) (أحمد محمد حسن ربايعة( (2019) تعني هذه الدراسة بتسليط الضوء على دور الإعلام في تعزيز القيم الوطنية، وتسعى لتقديم رؤية مقترحة لاستثمار وسائل الإعلام المتتوعة التقليدية والحديثة استثمارا نافعاً، وتوظيفها للمحافظة على قيم الأمة ومقدراتها والإبقاء على تماسكها وتعزيز انتمائها في ضوء التصور الإسلامي ومبادئه وقيمه، لاسيما في ظل المنعطفات الخطرة التي تعيشها الأمة العربية والإسلامية، وزيادة حجم التحديات والاختطاف والاستهداف الذي يواجهه شبابنا فضلا عن حملات التشكيك والنتويه المخطط لها، وتأني هذه الدراسة لتقدم رؤى مقترحة لتوظيف الإعلام في ترسيخ القيم والثوابت الوطنية لدى الثباب، والعمل على تفعيل دورهم وخرطهم في تحمل هذه المسؤولية الوطنية، لاسيما أنهم هم الأكثر استخداما لهذه الوسائل والأنشط ممارسة لها ويضاف إلى ذلك أنهم 
الأكثر استهدافا واختطافا. وقد اعتمد البحث المنهج الاستقرائي والمنهج التحليلي لتحقيق أهداف هذه الدراسة بإطاريها النظري والتنظيري، وخلص البحث إلى تقديم مقترحات عملية لتوظيف أبرز وسائل الإعلام في تعزيز القيم الوطنية لدى المواطنين.

\section{4) نورة عمر العتيبي(2018)}

هدفت الدراسة إلى التعرف إلى قيم المواطنة لدى طلبة جامعة الملك سعود، حيث اقتصرت الدراسة على دراسة (الانتماء، الولاء، الحريات العامة) كقيم للمواطنة، وهدفت للتعرف إلى مفهوم المواطنة ودرجة تمثلهم لقيم المواطنة، والتعرف إلى الفروقات حسب الجنس، التخصص، المستوى التعليمي للوالدين، الخلفية الاجتماعية للأسرة، والدخل الثهري للأسرة، وللوصول للنتائج استخدمت الباحثة الاستبانة؛ إذ بلغ مجموع عينة الدراسة الممثلة لمجتمع الدراسة (384)مفردة طبقت على طلبة جامعة الملك سعود في الرياض، وتوصلت الدراسة إلى عدة نتائج، من أهمها: ارتفاع درجة تمثل الطلبة لقيم المواطنة في جميع أبعادها، ولم توجد فروقات جوهرية على مقياس قيم المواطنة لاى طلبة جامعة الملك سعود تتعلق بالجنس أو التخصص أو لخلفية الاجتماعية أو الدخل الثهري للأسرة أو المستوى التعليمي للأم، بينما اتضح وجود فروق بين متوسطات درجات الطلبة على لـ له بعد الانتماء طبقا لاختلاف المستو ى التعليمي للأب. 5) حسيبة ناريمان بلعباس(2018) نعالج الورقة البحثية واقع قيم المواطنة في الأعمدة الصحفية الجزائرية (نقطة نظام بصحيفة الخبر ) كأنموذج تطبيقي، وكيفية تتاولها لهذه القيم في معالجتها لمختلف القضايا الوطنية وهذا من خلال التطرق إلى طبيعة القيم المكونة للنص الإعلامي، علاوة على ذلك نهدف إلى معرفة الاستراتيجيات الإقناعية التي حظيت بالاهتمام في العمود الصحفي "نقطة نظام"، وبالموازاة مع ذلك نسعى إلى استتباط نوعية الأطر الإقناعية التي احتوت قيما دون أخرى، ويعتبر هذا التضمين ضروري لأنه يكسب لقيم المواطنة دلالة رمزية معينة، وهذا كلّه من شأنه أن يكثف لنا الصورة الواقعية لقيم المواطنة في الخطاب الإعلامي. 6) محمد عبد البديع السيد(2016) 
يسعي البحث للتعرف علي دور وسائل الإعلام الاجتماعية في نشر نقافة المواطنة الرقمية لدي طلاب الجامعة، واستقراء طبيعة مفهوم المواطنة الرقمية لاى طلبة الجامعة، والوقوف على الفروق بين طلبة الجامعة فيما يتعلق بالمواطنة الرقمية ومتغير الجنس، الخلفية الاجتماعية، المستوى الاقتصادي، ومستوى تعليم الوالدين • مجتمع البحث وحجم العينة؛ يتكون مجتمع البحث من طلبة وطالبات جامعات بنها الذين يدرسون في الكليات النظرية (الآداب - الحقوق - التربية) والكليات العملية (العلوم - الهندة - الطب البيطري - التجارة) اختار الباحث منهم عينة عمدية بالمصادفة بلغت (101 مفردة ) روعي فيها أن تتنوع إقامتهم في القري والمدن .أهم النتائج: طلاب وطالبات الكليات العملية عينة الدراسة أكثر استخداما لمواقع التواصل الاجتماعي حيث بلغت نسبتهم 64.5 \% وفي حين بلغت نسبة طلاب وطالبات الكليات النظرية 35.5\% ، جاء موقع الفيس بوك في مقدمة الوسائل الاجتماعية الأكثر استخداما من قبل طلاب الجامعة عينة الدراسة، نسبة 91.4 \% من طلاب وطالبات الجامعة عينة الدراسة أجمعوا علي أنهم لا يعرفون معني المواطنة الرقمية سواء كانوا ذكور أو إناثا ولا فرق بين طلاب الكليات العملية والكليات النظرية، طالبت نسبة 45.4\% من طلاب وطالبات الجامعة بفرض رقابة على استخدام وسائل الإعلام الجديدة، كما أكدوا أن وسائل الإعلام الجديدة تساهم في ازدراء الأديان.

(2016) غربية، سمراء) (1) ترجع أهمية الموضوع الذي سيتم تتاوله في هذه الورقة العلمية في الطرح الذي يؤيده البعض من أن إثكالية الهوية الثقافية تختلف في عصر ثورة الاتصالات والعولمة عن عصور الاستعمار والكفاح للاستقلال وبناء الدولة القومية، حيث أن الهوية الثقافية في عصر العولمة وثورة الاتصال ترتبط بفضاء طبيعي وإلكتروني تتفاعل فيه فواعل اقتصادية وثقافية وإعلامية وسياسية وإنسانية في عالم مترابط - صرف النظر عن تتاقضاته واختلالاته التي لا نعالج بالانعزال عنه بل الاندماج فيه والمشاركة في تعديل شروط توازناته وإعادة صياغة مفاعيله الداخلية. 8) (2015) (أمل بلر الدويلة (20) 
هدفت الدراسة الحالية إلى بحث قيم المواطنة لدى طلبة الجامعة بدولة الكويت في ضوء بعض المتغيرات من خلال دراسة الفروق في قيم المواطنة التي يمكن عزوها إلى متغيرات: الجنس (ذكور - إناث) والفرقة الدراسية (طلبة الفرقة الأولى وطلبة الفرقة الرابعة)، والتخصص (التخصصات الأدبية وطلبة التخصصات العلمية)، والسكن (طلبة المناطق الداخلية وطلبة المناطق الخارجية). تم استخدام المنهج الوصفي التتبؤي. كما تم تطبيق مقياس قيم المواطنة إعداد الباحثة على عينة الدراسة التي تكونت من (•ـــ) طالب وطالبة بواقع

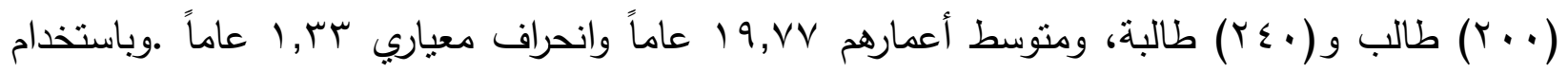
المعالجات الإحصائية التي تمثلت في: اختبار "ت" لدلالة الفروق بين المتوسطات غير المرتبطة، وتحليل الانحدار المتعدد التدريجي. أظهرت النتائج وجود فروق ذات دلالة إحصائية بين متوسطي درجات الذكور والإناث في قيم المواطنة لصالح الإناث. كما بينت النتائج وجود فروق ذات دلالة إحصائية بين متوسطي درجات طلبة الفرقة الأولى وطلبة الفرقة الرابعة لصالح طلبة الفرقة الرابعة. كما بينت النتائج عدم وجود فروق ذات دلالة إحصائية بين منوسطي درجات طلبة الأدبي وطلبة العلمي في قيم المواطنة، وكذلك عدم وجود فروق ذات دلالة إحصائية بين منوسطي درجات طلبة السكن الداخلي والخارجي في قيم المواطنة، كما كان عامل الجنس أهم عامل من العوامل المستقلة التي تسهم في التتبؤ بقيم المواطنة حيث فسر .., ب؟ من التباين في قيم المواطنة، يليه التخصص والذي فسر ــ, ٪ من هذا التباين.

\section{9) رويد أحمد طلب أحمد محمد(2014)}

هدفت الدراسة .تقديم دراسة تحليلية لصحيفتي " الوفد - الحرية والعدالة عام 2011"في ضوء معالجة الخطاب الصحفي لقيم المواطنة في المجتمع المصري. اعتمد البحث على مسح البحوث والدراسات السابقة المرتبطة بالموضوع، وتحليل عينة استطلاعية من الأخبار المتعلقة بقيم المواطنة المنشورة بهذه الصحف، لتحديد أطروحات قيم المواطنة والقضايا المرتبطة بها في إطار السياق الاجتماعي العام للمجتمع المصري، أيضاً استخدم أسلوب تحليل الخطاب للأخبار الخاصة بقيم المواطنة المنشورة بصحيفة الوفد وصحيفة الحرية 
والعدالة. وتكونت مجموعة البحث من التنظيمات الصحفية الحزبية في مصر ممثلة في صحيفة الوفد الحزبية، وصحيفة الحرية والعدالة. وتمنلت أدوات البحث في أداة تحليل مسارات البرهنة، كما تم استخدام أداة تحليل القوى الفاعلة، التي تقوم على تحليل خطاب محدد لمجموعة من الفاعلين ذوي الأهمية، ورصد الأفعال والأدوار أو الصفات المنسوبة لهم. وتوصل البحث إلى عدة نتائج، منها تحليل خطاب صحف الدراسة أن كلا من الوفد، الحرية والعدالة قد اتفقتا على ترتيب قيمة الديمقراطية، حيث تأتى في الترتيب الأول على رأس قائمة قبم المواطنة المنشورة بهما خلال فترة الدراسة. كما أقتصر تتاول صحيفة الحرية والعدالة لقيمة الديمقراطية على البعد السياسي لها، تمتل في المشاركة في الانتخابات ودعم التمنل النيابي للأحزاب في البرلمان، بما يخدم أهداف حزب الحرية العدالة في المرحلة الحالية في حوض الانتخابات التشريعية والرئاسية والحصول على مقاعد للحزب الممثل للإخوان المسلمين في البرلمان 10)دراسة حنان حامد (2012) هدفت الدراسة إلى التعرف على مفهوم المواطنة ومستويات ومجالات وأبعاد وتوضيح التذاخلات بين وبين بعض المفاهيم الأخرى ، كما هدفت إلى دراسة ثقافة المواطنة لدى طلاب التعليم الثانوي الفني ، وتوصلت الدراسة إلى أن المعلم من أهم عناصر العملية التعليمية الذي له دور بارز في نشر نقافة المواطنة ، وأن المقررات الدراسية المختلفة تساعد المعلم في توضيح معنى المواطنة ، كما توصلت الدراسة إلى أن الإدارة المدرسية التي تتسم بالنمط الديموقراطي ينوافر فيها الاحترام المتبادل للآراء.

11) يعقوب يوسف الكندري(2011)

تركز الدراسة على مفهومي المواطنة والانتماء من الجانب التطبيقي والممارس في سلوك الأفراد، وتحديدا سلوك الثباب داخل المجتمع الكويتي، فهي تحاول أن تكثف عن الاختلافات الاجتماعية والثقافية في تحديد سلوك المواطنة والانتماء لدى شريحة مهمة ورئيسة داخل المجتمع، متمثلة بشريحة الثباب، وكذلك تحاول الكثف عن علاقة هذين المفهومين ببعض المتغيرات الاجتماعية والثقافية داخل المجتمع الكويتي. لقد شملت عينة الدراسة 621 مستجيبا ومستجيبة من فئة الثباب، تراوح أعمارهم بين 17 -25 سنة، (389 من الذكور، 
232 من الإناث). وقد بلغ متوسط أفراد العينة 20.94، (ع=2.05 .(اعتمدت الدراسة على الاستبانة وسيلة لجمع البيانات، واحتوت على مجموعة من المتغيرات الأساسية والديموغرافية. هذا، بالإضافة إلى الاعتماد على مقياسي الانتماء والمواطنة مرا بإجراءات الصدق والثبات المعتادة. وأدخلت البيانات في البرنامج الإحصائي SPSS ، وتم الاعتماد على الأساليب الإحصائية المتمنتة في معامل الارتباط، واختبار ت، واختبار مربع كاي، ومعامل الانحدار المتعدد. وقد كثفت أبرز نتائج الدراسة عن وجود علاقة إحصائية إيجابية بين قيم الانتماء وقيم المواطنة العامة وجميع أبعادها المتعددة، كذلك كثفت الدراسة عن وجود علاقة إيجابية ذات دلالة إحصائية بين قيم الانتماء ومتغير المستوى التعليمي، والمستوى الاقتصادي. ولم تكثف الدراسة وجود أب فروق ذات دلالة إحصائية بين الذكور والإناث من فئة الثباب، وكذلك بين أفراد العينة من معتتقي المذهبين السني والجعفري في معدلات قيم الانتماء والمواطنة.

12)دراسة حنان مراد وجنان مالكي ( 2011) طبقت الدراسة على عينة من طلبة الاعلام والاتصال السنة الرابعة وبلغ عددهم 323 طالبا وطالبة (205 اناث 118 ذكور واستخدم الباحث المقابلة والاستبيان وتوصلت الدراسة إلى : - ظهر تتاقض في بنية الوعي والصورة الذهنية لدى الثباب عن بعض المفردات المرتبطة بالتعددية، والانفتاح على الآخر ، والحرية والمشاركة السياسية - انقسمت أراء المبحوثين بين التردد تارة بين الإقبال على الفكر المطروح عبر وسائل الاتصال والإعلام وبين التمسك بالجذور وما وقر في ضمير المجتمع من مفاهيم وقناعات سياسية وثقافية واجتماعية. دلت الدراسة على حالة من الصراع الفكري والأيديولوجي بين التيارات الفكرية والعقائدية المتواجدة في الساحة الجزائرية سواء ذات البعد الديني الداعي إلى وجوب الحفاظ على الخصوصية والهوية الذاتية أو التيارات ذات المنطلقات الغربية الوافدة الداعية إلى التحررية والانفتاح. - ظهور قصور واضح في دور العديد من مؤسسات المجتمع الثقافية والتعليمية في تشكيل ودعم وتتمية الوعي بالصورة التي تتطلبها غايات المجتمع، مستوعبة ما يحدث على أرض الواقع من أحداث وما ينفث 
من أفكار ، ساعية إلى تأكيد استمرارية الاحتفاظ بالجذور وتتمية الإحساس بالهوية والانتماء لدى الثنباب

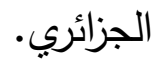

13)دراسة وسام صقر(2010)

هدفت هذ الدراسة إلى الكثف عن انعكاس اختلال مفهوم التقافة السياسية على مفهوم المواطنة لدى

الثباب الجامعي الفلسطيني، واستخدت الدراسة المنهج التاريخي بالإضافة إلى المنهج الوصفي التحليلي ، وأوضحت الدراسة أن الانقسام الفلسطيني أظهر حالة من تقلص مساحة الحيز العام بما في ذلن مساحة الحر ات والحقوق ، مما غيب الثفافية والمساءلة الثعبية والسياسية ، وأفضى حالة من انعدام الثقة بالنظام السياسي القائم ، كما أوضحت الدراسة أن قيم المواطنة التي يجب أن يلتزم بها الثباب الجامعي هي : حب الوطن ، الانتماء والولاء ، الحرة ، المشاركة ، الجماعية.

14)دراسة عثمان أحمد العصفور (2009)

هدفت الدراسة التعرف إلى أراء المواطنين الكويتيين حول العوامل التي تزيد من الإحساس والثعور

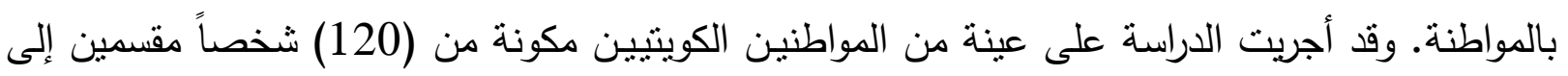
ثلاثة مجموعات وهم مجموعة الطلاب الجامعيين، ومجموعة الخريجين، ومجموعة الموظفين، وقد استخدم الباحث المنهج الوصفي التحليلي لتحليل البيانات والمعلومات التي تم جمعها باستخدام أداة مقننة للاراسة، حيث تم استخدام المتوسطات الحسابية والانحرافات المعيارية وتحليل التباين الأحادي وتحليل التباين المتعدد. وقد أظهرت الدراسة أن هناك فروق بين الذكور والإناث في أربعة أبعاد هي بعد العادات والتقاليد، البعد المعرفي وبعد المهارات والبعد الاجتماعي وبعد المساواة وتكافؤ الفرص وكانت الفروق لصالح الإناث في جميع الأبعاد، بينما لم تظهر الدراسة وجود فروق في بقية الأبعاد الأخرى كالبعد الديني، والقيمي، والوطني والتربوي. كما أظهرت الدراسة وجود فروق بين مجموعات الطلاب، الخريجين، الموظفين في بعدين هما البعد القيمي والبعد الاجتماعي وذلك بين الطلبة الخريجين والجامعيين. 
هدفت الدراسة التعرف إلى نأثير الجامعة في تعليم الطلاب حقوق وواجبات المواطنة وأدوارهم في المجتمع الأمريكي, حيث استخدم الباحث المنهج الوصفي, وتوصلت الدراسة إلى مجموعة من النتائج منها أن ممارسة الطلاب للأنشطة داخل الجامعة وخارجها واثنتراكهم في الحوارات والمناقثات مع المعلمين واثتراكهم في قضايا ومشكلات المجتمع وفهم الموضوعات الاجتماعية والسياسية داخل الجامعة وخارجها وإعدادهم للتعامل مع التحديات التي تواجهم في الحياة وتعليمهم الأسلوب الديمقراطي ساهم في غرس وتدعيم قيم المواطنة لديهه.

التعليق على الاراسات السابقة: -

يتضح من العرض للاراسات السابقة التي وقعت بين يدي الباحث الملاحظات التالية: •ـ ندرة الدراسات العربية ذات العلاقة المباشرة بمجال البحث في - حدود علم الباحث- ولاسيما في

$$
\text { المجتمع الكويتي. }
$$

•. ثتاول الدراسة الحالية تحليل قضايا المواطنة في الصحف الكوينية المطبوعة. •. استفادة الدراسة الحالية من الدراسات السابقة في تحديد محاور استمارة تحليل المضمون. سابعاً: النظرية المستخدمة في الاراسة : يمكن عرض إحدى النظريات الإعلامية التي يمكن في ضوئها تفسير معالجة الصحف الكويتية لقضـايا Framing Analysis حقوق الإنسان. وتتمثل في نظرية تحليل الإطار الإعلامي تقدم نظرية تحليل الإطار الإعلامي تفسيرا منتظما لدور وسائل الإعلام في تثكيل الأفكار والاتجاهات حيال القضايا البارزة وعلاقة ذلك باستجابات الجمهور المعرفية والوجدانية لتلك القضايا. وتفترض هذه النظرية أن الأحداث لاتنطوى فى حد ذاتها على مغزى معين، وإنما تكتسب مغزاها من خلال وضعها في إطار Frame يحددها وينظمها ويضفي عليها قدرا من الاتساق من خلال التركيز على بعض جوانب الموضوع وإغفال جوانب أخرى . 
والإطار الإعلامي لقضية ما يعني انتقاء متعد لبعض جوانب الحدث أو القضية وجعلها أكثر بروزا فى النص الإعلامي، واستخدام أسلوب محدد في توصيف المشكلة وتحديد أسبابها وتقييم أبعادها وطرح حلول مقترحة بشأنها. ويحد Entman أربع وظائف لتحليل الإطار الإعلامي هى: Define Problem تحديد المشكلة أو القضية بدقة. Diagnose Causes . تشخيص أسباب المشكلة Moral Judgements . وضع أحكام أخلاقية

Suggest Remedies اقتزاح سبل العلاج.

ويشير إنتمان إلى إمكانية تتاول الأطر الإعلامية وفق مستويين أساسيين : يتعلق الأول: بتحديد مرجعية تساعد في عملية تمثيل المعلومات واسترجاعها من الذاكرة. أما المستوى الثاني فيتعلق بوصف السمات التى تمتل محور الاهتمام فى النص الإعلامي. ومن خلال التكرار والتثعيم يتم إبراز إطار بعينه ينطوى على تفسيرات محدة تصبح بدورها أكثر قابلية للإدراك والتذكر من جانب الجمهور الذي يتعرض لتلك الوسيلة الإعلامية(Entman, R.M. (1991) vol.41, no.4). وقد وجدت العديد من البحوث في مجال السياق الإخباري كيف أن هذه الأطر تقود فكر المتلقي, وتؤكد دراسات التأثير هذا المبدأ الذي يربط بين الإطار Sharon Hartin, 1996:98-) الإعلامي ورؤية الأفراد للمسئولية الاجتماعية وأثره على معارف الجمهور ل

ويتحكم في تحديد الإطار الإعلامي خمسة متغيرات أساسية هى: 1. مدى الاستقلال السياسي لوسائل الإعلام: حيث أن بعض الوسائل ترتبط بسياسة الدول أو الحكومات وبالتالي يتأثر الإطار الإعلامي لهذه الوسائل. 2. نوع مصادر الأخبار : من فضائيات أو صحف أو غيرها. 3. 3 أنماط الممارسة الإعلامية. 
4. المعتقدات الأيديولوجية والثقافية للقائمين بالاتصال: حيث توجه المعتقدات الأيديولوجية مادة الاتصال. 5. طبيعة الأحداث ذاتها: هل تحكمها توجهات أيديولوجية ؟ هل تتأثز بالنظام السياسي وتوجهاته؟ (Wolfsfeld, G., 1991, pp15-18)

ويجب التفريق بين نمطين أساسيين للأطر الإعلامية هما: 1. الإطار المحدد المرتبط بوقائع ملموسة Episodic Frame ويركز على شرح القضايا والوقائع

الملموسة.

2. الإطار العام Thematic Frame ويعالج القضايا في سياق مجرد كتفسير أسباب واقعة معينة.)

$$
\text { السيد و مكاوي، 2004، ص ص 248-350) }
$$

تساعدنا نظرية تحليل الإطار على فهم واستيعاب الإطار الذى تتاقش من خلاله الصحف الكوينية لقضايا المواطنة وذلك من خلال تحليل مضمون هذه القضايا المقدمة عبر بعض الصحف الكوينية, وتوضيح كيفية قيام الصحف الكويتية في تتاولها لقيم المواطنة بتحديد المشكلة أوالقضية ، وتتخيصها، وكثف أسبابها، وأساليب العلاج المقترحة ومدى تكرار وتدعيم إطار بعينه ينطوي على تفسيرات بعينها تكون أكثر قابلية وإدراك

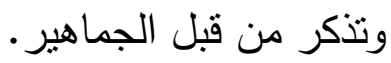

من خلال الإطار النظري السابق يمكن دراسة القضايا التي تعالجها الصحف، ومساحة العرض، وأسلوب عرض هذه القضايا، والفنون الصحفية ، مصادر المادة الصحفية، ووسائل إبراز الصحف لقضايا المواطنة.

ثامناً: الإجراءات المنهجية للاراسة: (1) نوع الدراسـة : تتنمي هذه الدراسـة إلى الدراسـات الوصفية التحليلية في المجال الإعلامي، التي يهدف إلى رصـد و تحليل خصـائص المضـمون المقدم على صـفحات الصـف - محل الدراسـة - حول قضـايا المواطنة ، من حيث مؤثـرات عديدة منها : حجم الاهتمام، قوالب التحرير الصـحفية، توجهات المعالجة 
الصحفية، و ذلك بالاعتماد على العرض الكمي والكيفي للبيانات التي يمكن توفيرها من خلال منهج تحليل

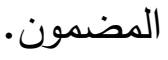

$$
\text { (2) (2) منهج الدراسة: }
$$

تعتمد هذه الدراسة على منهجين للإجابة على تساؤلاتها هما :

(أ) منهج المسح الإعلامي: وهو من أهم المناهج المستعملة في البحث العلمي، يلجأ إليه الباحث عندما تتوفر لايه معرفة مسبقة (بحوث استطلاعية أو وصفية سابقة) عن أبعاد أو جوانب الظاهرة المراد دراستها ـ ويساعد هذا المنهج على وصف وتحليل مضمون المادة الصحفية حول قضايا المواطنة في صحف الدراسة. (ب) المنهج المقارن: المنهج المقارن يساعد في مقارنة النتائج الكمية والنوعية بين الوحدات المدروسة؛ ليتم على أساسها وضع استتناجات ثُبين مستوى استخدام استراتيجية معالجة الصحف الكويتية لقضايا المواطنة، وبناءاً على ذلك يتم استتناج أسباب القوة والضعف بين الوحدات المدروسة .وفقاً لفرضيتي الدراسة.للمقارنة بين ثلاث صحف كوينية.

(3) مجتمع الدراسة : تركز مجتمع الدراسة التحليلية في المضامين الصحفية التي تتتاول بقضايا المواطنة. (4)عينة الدراسة: وهى الصحافة المطبوعة (صحيفة الوطن- جريدة النهار الكويتية-جريدة الراي الكوينية)، التي تخضع للاراسة . الفترة الزمنية : يتم مسح شامل لمدة ستة أشهر والمدة المحددة للبحث وهى (من بداية يناير 2019 وحتى نهاية يونية 2019)، وترجع مبررات اختيار هذه الصحف نظرا لاختلاف توجهاتها الأيديولوجية مابين حكومية ومعارضة وهو ما يمكن أن يعكس تتوعا واختلافا في عرض ومناقتة قضايا المواطنة. (5)أداة الدراسة: نم استخدام صحيفة تحليل مضمون. حيث يعتبر تحليل المضمون من أكثر الأدوات استخدامًا في تحليل المواد الصحفية المنشورة في الصحف والمجلات للوصول إلى معرفة العقلية الكامنة وراء هذا الإتتاج الإعلامي والدعائي (حسين، 2006, ص26) 
فيما يتعلق بتحليل مضـمون أطر معالجة الصــف الكويتية المطبوعة لقضـايا المواطنة ، فقد كانت نتائج التحليل كما يلي:
جدول رقم (1) - (1) - (1)

الفنون الصحفية المتبعة في عرض قضايا المواطنة في صحف الدراسة

\begin{tabular}{|c|c|c|c|c|c|c|c|c|}
\hline \multicolumn{2}{|c|}{ الاتجاه العام } & \multicolumn{2}{|c|}{ جريدة الراي } & \multicolumn{2}{|c|}{ جريدة النهار } & \multicolumn{2}{|c|}{ صحيفة الوطن } & \multirow{2}{*}{ الكمي } \\
\hline$\%$ & ك) & $\%$ & ك5 & $\%$ & 5 & $\%$ & ك & \\
\hline 48.6 & 305 & 39.8 & 70 & 50.0 & 100 & 53.8 & 135 & الإخبار \\
\hline 13.2 & 83 & 19.3 & 34 & 15.5 & 31 & 7.2 & 18 & النقد والتقويم \\
\hline 14.5 & 91 & 21.6 & 38 & 15.5 & 31 & 8.8 & 22 & التتاقشية \\
\hline 11.6 & 73 & 10.2 & 18 & 14.0 & 28 & 10.8 & 27 & وحلوال \\
\hline 5.6 & 35 & 4 & 7 & 3 & 6 & 8.8 & 22 & صحفي التحقيق \\
\hline 6.4 & 40 & 5.1 & 9 & 2 & 4 & 10.8 & 27 & المقال \\
\hline 100 & 627 & 100 & 176 & 100 & 200 & 100 & 251 & المجموع \\
\hline
\end{tabular}


تعددت الأسـاليب المتبعة في عرض قضــايا المواطنة على مسـتوى كل صــيفة ، وبدراسـة بيانات الجدول السابق رقم ( 1 ) يتبين أن الفنون التي استخدمت في تقديم قضايا المواطنة في صحف الدراسة كانت كالتالي : 1- الإخبار : احتل هذا النوع المرتبة الأولى في جميع صحف الدراسة بنسبة 48.6\%، واستخدم بنسب منقاربة في كل من جريدة " الوطن " " و" جريدة النهار الكويتية " إذ تراوحت ما بين 50\% إلى 53.8\% ، في حين لم تتجاوز نسبتها في جريدة " جريدة الراي الكويتية " 39.8\% . 2- التتاقتــية : بنسـبة 14.5\% و و بلغ عدد تكراراتها في " جريدة الراي الكويتية " 38 تكراراً ، بنسبة 21.6\%؛ وفي " جريدة النهار الكويتية " 31 نكراراً ، بنسبة 15.5\% ، وفي " الوطن " 22 نكراراً ، بنسبة 8.8\% . 3- النقد والتقويم : بنسبة.13.2\% جاءت جريدة الراي الكويتية في مقدمة صـحف الدراسـة من حيث اسـتخدامها لهذه الأساليب ، إذ لها 34 تكراراً ، بنسبة 19.3\% ، تبعتها " جريدة النهار الكويتية " ولها 31 تكراراً ، بنسبة 15.5 \% ، ثم " الوطن " ولها 18 نكراراً ، بنسبة 7.2 \% . 4- الاقتراحات والحلول : استخدمت جريدة " جريدة النهار الكوينية " هذا النوع أكثر من الصحف الأخرى، إذ بلغ عدد تكراراته 28 تكراراً ، بنسـبة 14\% ، في حين تراوحت نسـبة اسـتخدامه في الصــف الأخرى ما بين \% \% 10.2 ، إلى 10.8 5- المقال بنسبة 6.4\% وارتفع استخدامه في جريدة الوطن بنسبة 10.8\%. 6- التحقيق الصحفي بنسبة6.5\% وارتفع استخدامه في جريدة الوطن بنسبة 8.8\%

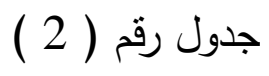
يوضح تكرار ومساحة موضوعات بقضايا المواطنة في صحف الدراسة

\begin{tabular}{|c|c|c|c|c|}
\hline \multicolumn{2}{|c|}{ المساحة } & \multicolumn{2}{|c|}{ التكرار } & التوزيع الكمي \\
\hline$\%$ & سم2 & $\%$ & ك5 & الصحيفة \\
\hline 39.00 & 107615 & 24.3 & 251 & صحيفة الوطن \\
\hline
\end{tabular}




\begin{tabular}{|c|c|c|c|c|}
\hline 38.44 & 106029 & 19.3 & 200 & جريدة النهار الكوينتة \\
\hline 22.54 & 62184 & 17.00 & 176 & جريدة الراي الكوينية \\
\hline 100 & 275828 & 100 & 627 & المجموع \\
\hline
\end{tabular}

يبين جدول( 2 ) تكرار ومسـاحة موضـوعات بقضـايا المواطنة في صحف الدراسـة كانت كالتالي : صـحيفة الوطن ارتقعت نسـبة المسـاحة لتصـل الى 39.00\% وكان التكرار بنسـبة 24.3\% وفى جريدة النهار الكويتية ارتفعت نســبة المســاحة وكانت 38.4\% والتكرار بنســبة 19.3\% أما عن جريدة الرأى الكوينية كانت المساحة 22.5\% والتكرار بنسبة 17.0\% .

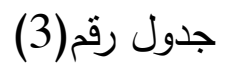

يوضح نكرار نسب بقضايا المواطنة في صحف الدراسة

\begin{tabular}{|c|c|c|c|c|c|c|c|c|}
\hline \multicolumn{2}{|c|}{ الاتجاه العام } & \multicolumn{2}{|c|}{ جريدة الراي } & \multicolumn{2}{|c|}{ جريدة النهار } & \multicolumn{2}{|c|}{ صحيفة } & \multirow{2}{*}{ القضايا التوزيع الكمي } \\
\hline$\%$ & ك & $\%$ & ك5 & $\%$ & 5] & $\%$ & 5 & \\
\hline 41.5 & 260 & 50.6 & 89 & 41.00 & 82 & 35.5 & 89 & 1. إعلاء ســـيادة الدولة \\
\hline 19.5 & 122 & 17.00 & 30 & 20.00 & 40 & 20.7 & 52 & 2. التـأكيـد على الحقوق \\
\hline 9.9 & 62 & 9.1 & 16 & 11.00 & 22 & 9.6 & 24 & 3. التأكيد على المســاواة \\
\hline
\end{tabular}


العقى المجالمه - الجزي الأول(2021)

Gos.d.

"العلوم الاجتماعيةوالإسانية "

\begin{tabular}{|c|c|c|c|c|c|c|c|c|}
\hline 6.2 & 39 & 4.00 & 7 & 5.5 & 11 & 8.4 & 21 & 4. أمام القضاء التأكيد على المســـاواة \\
\hline 3.7 & 23 & 1.7 & 3 & 3.00 & 6 & 5.6 & 14 & 5. التأكيد على المســـاواة \\
\hline 2.4 & 15 & 0.6 & 1 & 2.5 & 5 & 3.6 & 9 & 6. التأكيد على المســاواة \\
\hline 16.3 & 102 & 16.5 & 29 & 17.00 & 34 & 15.5 & 39 & 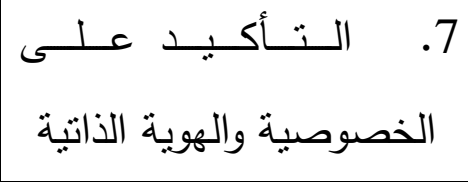 \\
\hline 10.5 & 66 & 11.9 & 21 & 9.5 & 19 & 10.3 & 26 & 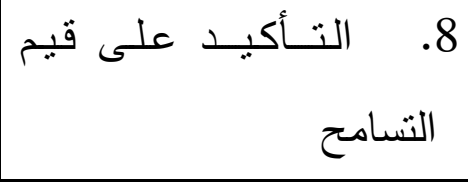 \\
\hline & 627 & & 176 & & 200 & & 251 & المجموع \\
\hline
\end{tabular}

بدراسة بيانات الجدول( 3) يتضح أن أولويات اهتمام صحف الدراسة بقضايا المواطنة متقارب إلى

حد كبير من حيث التكرار والمساحة .

فيما يتعلق بإعلاء ســيادة الدولة داخليا وخارجيا احتل هذا النوع المرتبة الأولى في جميع صـــف

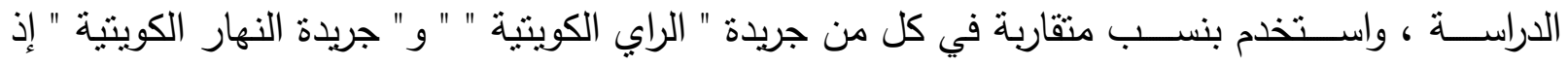

تراوحت ما بين 41.0\% و 50.6\% وكانت صحيفة الوطن بنسبة 35.5\% .

وفيما يتعلق بالتأكيد على الحقوق والواجبات للفرد والمجتمع ارتفعت نسـبة تكرارات صــحيفة الوطن

بالمقارنة بالصـــف الأخرى حيث كانت 20.7\% وكانت نســبة التكرارات فى صـــــــة النهار الكويتية

20.0\% ونسبة تكرارات صحيفة الراي الكويتية 17.0\%. 
أما عن التأكيد على الخصـوصـية والهوية الذاتية ارتفعت نسـبة التكرارات فى جريدة النهار الكويتية وكانت 17.0\% فى حين أن نســبـة التكرارات فى جريدة الراي الكوينيـة 16.5\% وفى جريدة الوطن .$\% 15.5$

وفيما يتعلق بالتأكيد على قيم التشــامح بنسـبة 10.5\% كانت نســبة التكرارات فى جريدة الوطن 10.3 فى حين أن جريدة الراي الكويتية 11.9\%، و جريدة النهار الكويتية 9.5\%. أما عن التأكيد على المساواة في المنافع الاجتماعية كانت نسبة التكرارات فى جريدة النهار الكويتية 11.0\% وفى جريدة الوطن 9.6\% وفى جريدة الراي الكويتية 9.1\% ـ وهو ما يدعم الانتماء. وفيما يتعلق بالتأكيد على المســاواة أمام القضــاء كانت نسـبة التكرارات فى جريدة الوطن 8.4\% فـى حين أن نســبة التكرارات فى جريدة النهار الكوينية 5.5\% وجريدة الراي الكويتية 4.0\%. والتأكيد على المساواة في القانون والدستور كانت نسبة التكرارات فى جريدة الوطن 5.6\% وفى جريدة النهار الكويتية 3.00وفى جريدة الراي

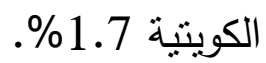
وفيما يتعلق بالتأكيد على المساواة في الوظائف كانت نسبة التكرارات فى جريدة الوطن 3.6\% فى حين أن نسبتها فى جريدة النهار الكويتية 2.5\% وفى جريدة الراي الكويتية 0.06\%. جدول رقم ( 4 ) يبين مساحة ونسب قضايا المواطنة في صحف الدراسة

وفيما يتعلق بمساحة قضايا المواطنة في صحف الدراسة ارتفعت نسبة قضية إعلاء سيادة الدولة داخليا وخارجيا بنسبة37\% جاءت جريدة الراي الكوينية في المرتبة الأولى بنسبة 48.7\% ثم جاءت قضية التأكيد على الحقوق والواجبات للفرد والمجتمع في المرنبة الثانية بنسبة27\%، وارتفعت في جريدة النهار الكويتية بنسبة 28.6\% وصحيفة الوطن بنسبة27.4\%. ثم جاءت قضية التأكيد على الخصوصية والهوية الذاتية في المرتبة الثالثة بنسبة 15.5\%، وكانت جريدة الراي الكوينية بنسبة 17.6\%. ثم جاءت قضية الفخر والاعتزاز بالوطن في المرتبة الرابعة بنسبة7.5\%، ثم 
العتى الثلاليه - الجزء الأرل (2021)

بهلة فئو

"العلور الاجتماعيةوالإنسانية"

\begin{tabular}{|c|c|c|c|c|c|c|c|c|}
\hline \multicolumn{2}{|r|}{ الاتجاه العام } & \multicolumn{2}{|c|}{ جريدة الراي } & \multicolumn{2}{|c|}{ جريدة النهار الكويتية } & \multicolumn{2}{|c|}{ صحيفة الوطن } & \multirow[t]{2}{*}{ التوزيع الكمي } \\
\hline$\%$ & سم2 & $\%$ & سم2 & $\%$ & سم2 & $\%$ & سم2 & \\
\hline 37 & 102031 & 48.7 & 30270 & 38.2 & 40535 & 29.0 & 31226 & 1. إعلاء ســــادة الدولة \\
\hline 27 & 74588 & 23.8 & 14828 & 28.6 & 30279 & 27.4 & 29481 & 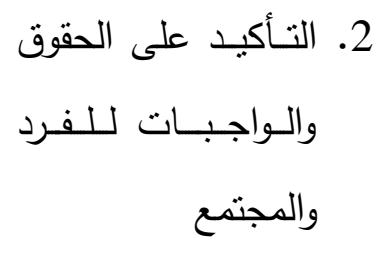 \\
\hline 5.4 & 15406 & 0.9 & 556 & 6.00 & 6321 & 7.9 & 8519 & 3. المســـاواة في المنافع \\
\hline 7.5 & 20820 & 7.3 & 4521 & 7.00 & 7442 & 8.2 & 8857 & 4. الـــــــر والاعـــزاز \\
\hline 3.3 & 9217 & 1.00 & 612 & 2.3 & 2400 & 5.8 & 6205 & 5. الدســـاواة في القانون \\
\hline 0.8 & 2330 & 0.4 & 221 & 0.0003 & 28 & 1.9 & 2091 & 6. المســاواة في الوظائف \\
\hline 15.5 & 42824 & 17.6 & 10965 & 15.4 & 16280 & 14.5 & 15579 & 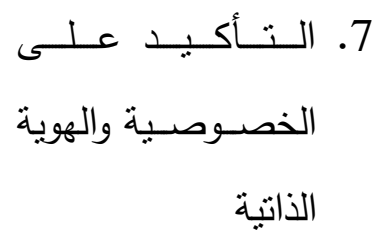 \\
\hline 3.1 & 8650 & 0.4 & 221 & 2.6 & 2772 & 5.3 & 5657 & 8. التأكيد على قيم \\
\hline 100 & 275856 & 22.5 & 62184 & 38.4 & 106057 & 39 & 107615 & المجموع \\
\hline
\end{tabular}


قضية المساواة في المنافع الاجتماعية بنسبة5.4\%، ثم جاءت قضية المساواة في القانون والدستور بنسبة3.3\%، ثم قضية التأكيد على قيم التسامح بنسبة 3.1\%، ثم جاءت قضية المساواة في الوظائف العامة.

- مصادر تغطية قضايا المواطنة على مستوى كل صحيفة : جدول رقم ( 5 ) ييين تكرار ونسب مصادر تغطية قضايا المواطنة في صحف الدراسة

\begin{tabular}{|c|c|c|c|c|c|c|c|c|}
\hline \multicolumn{2}{|c|}{ الاتجاه العام } & \multicolumn{2}{|c|}{ جريدة الراي } & \multicolumn{2}{|c|}{ جريدة النهار } & \multicolumn{2}{|c|}{ صحيفة الوطن } & \multirow{2}{*}{ المصدر } \\
\hline$\%$ & ك & $\%$ & ك & $\%$ & ك5 & $\%$ & ك & \\
\hline 18.7 & 117 & 28.4 & 50 & 12.0 & 24 & 17.1 & 43 & الصحف المحلية \\
\hline 10.8 & 68 & 14.8 & 26 & 14.0 & 28 & 5.6 & 14 & وكالات أنباء \\
\hline 15 & 94 & 11.4 & 20 & 27.0 & 54 & 8 & 20 & المندوب الصحفي \\
\hline 13.6 & 85 & 11.4 & 20 & 23.5 & 47 & 7.2 & 18 & الكتاب الرصاحفون \\
\hline 13.7 & 86 & 10.2 & 18 & 12.5 & 25 & 17.1 & 43 & المراسل \\
\hline 12.00 & 75 & 6.8 & 12 & 4.5 & 9 & 22.7 & 57 & الانترنت \\
\hline 5.7 & 36 & 5.7 & 10 & 2.5 & 5 & 8.4 & 21 & جهات حكومية \\
\hline 7.3 & 46 & 11.4 & 20 & 4.0 & 8 & 7.2 & 18 & وكالات أنباء إقليمية \\
\hline 2.7 & 17 & - & - & - & - & 6.8 & 17 & اسنماع \\
\hline
\end{tabular}




\begin{tabular}{|l|l|l|l|l|l|l|l|}
\hline 627 & 100 & 176 & 100 & 200 & 100 & 251 & المجموع \\
\hline
\end{tabular}

بدراسـة بيانات الجدول رقم (5) يتضـح تعدد المصـادر الصـحفية التي استخدمتها صـف الدراســة

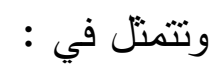

1- الصـــحف المحلية والأجنبية : جاءت جريدة " جريدة الراي الكويتية " في المقدمة ولها 50 تكراراً ، بنســـبة 28.4\% ، تلتها " الوطن " ولها 43 تكراراً ، بنسبة 17.1 \% ، وأخيراً جريدة النهار الكوينية ولها 24 نكراراً ، بنسبة 12\% .

2- وكالات الأنباء العالمية: احتلت " جريدة الراي الكوينية " ولها 26 نكراراً، بنســبة 14.8 \% ، تلتها " جريدة النهار الكويتية " ولها 28 نكراراً ، بنسبة 14\% ، وأخيراً " الوطن " ولها 14 نكراراً ، بنسبة 5.6 \% . 3- المندوب الصحفي: بلغ عدد الموضوعات التي وردت عن طريق أكثر من مصدر في جريدة " النهار الكويتية " 54 موضوعاً ، بنسبة 27\% ، و " جريدة الراي الكويتية "و " الوطن " لكل واحدة منهما 20 موضوعاً ،

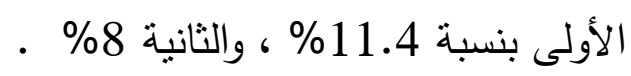

4- جهات حكومية : جاءت الجهات حكومية في جريدة وفي " الوطن " بنسـبة 8.4 \% ، وفي " جريدة الراي الكويتية " بنسبة 5.7 \% ، وفي " النهار الكويتية " بنسبة 2.5\% .

5- وكالات الأنباء الإقليمية : شغلت " جريدة الراي الكويتية " المركز الأول ، ولها 20 تكراراً ، بنسبة 11.4\% ،

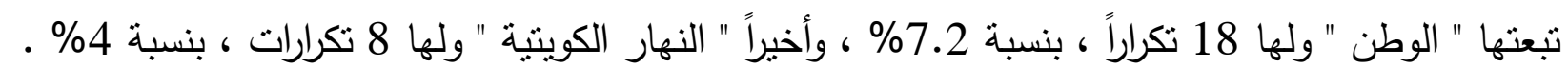
6- قسم الاستماع : استخدمت هذا المصدر فقط جريدة " الوطن " بنسبة 6.8 \% من مجموع المصادر الإعلامية في الصحيفة المذكورة .

- مواقع نشر قضايا المواطنة على مستوى كل صحيفة : جدول رقم ( 6 ) يبين تكرار ونسب مواقع قضايا المواطنة في صحف الدراسة 


\begin{tabular}{|c|c|c|c|c|c|c|c|c|}
\hline \multicolumn{2}{|c|}{ الاتجاه العام } & \multicolumn{2}{|c|}{ جريدة الراي } & \multicolumn{2}{|c|}{ جريدة النهار } & \multicolumn{2}{|c|}{ صحيفة الوطن } & \multirow{2}{*}{ التوزيع الكي } \\
\hline$\%$ & 5] & $\%$ & ك5 & $\%$ & ك & $\%$ & ك & \\
\hline 81.3 & 510 & 55.1 & 97 & 88.0 & 176 & 94.4 & 237 & الصفحات \\
\hline 18.7 & 117 & 44.9 & 79 & 12.0 & 24 & 5.6 & 14 & الصفحة الأولى \\
\hline 100 & 627 & 100 & 176 & 100 & 200 & 100 & 251 & المجموع \\
\hline
\end{tabular}

بدراسـة بيانات الجدول رقم (6) يتبين تكرار ونسـب مواقع نشـر قضـايا المواطنة في صـحف الدراسـة ، وذللك على النحو التالي : - الصفحات المتخصصـة : بلغ عدد الموضوعات المنشورة بهذه الصفحات في " صحيفة الوطن " 237 موضـوعاً ، بنسبة 94.4\% ، وفي " النهار الكوينية " 176 موضـوعاً ، بنسبة 88\% ، وفي " جريدة

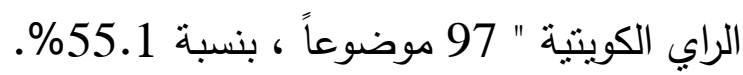
- الصــفحة الأولى : لاثـــك أن عرض قضــايا المواطنة في الصــفحة الأولى يؤكد على الاهتمام بهذه

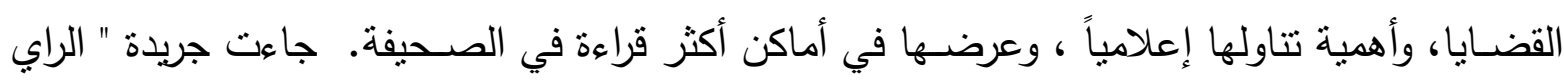
الكويتية " في المقدمة ولها 79 تكراراً ، بنســبة 44.9\% ، تلتها " النهار الكويتية " ولها 24 تكراراً ، بنســبة 12\% ، وأخيراً " صـــحيفة الوطن " ولها 14 نكراراً، بنســبة 5.6 \% من مجموع تكرارات كل صحيفة على انفراد . عاشراً: النتائج العامة والتوصيات: 
تنين من تحليل معالجة صحف الدراسة لقضايا المواطنة في المجتمع الكويتي ما يلي: - فيما يتعلق قضايا المواطنة التي عالتها صحف الدراسة: فقد أكدت نتائج الدراسة على اهتمام الصحف الكويتية بقضايا المواطنة وكانت في مقدمة هذه القضايا ؛ إعلاء سيادة الدولة داخليا وخارجيا بنسبة51.5\%، التأكيد على الحقوق والواجبات للفرد والمجتمع بنسبة19.5\% وقد توصلت دراسة سميرة لغويل(2019)" أن لقيم المواطنة دورا كبيرا في تطور المجتمعات وأن ترسيخها يتحقق من خلال توعية الأفراد وتعريفهم بحقوقهم وواجباتهم في المجتمع". ثم التأكيد على الخصوصية والهوية الذاتية بنسبة.16\%\%، التأكيد على قيم التسامح بنسبة10.5\%، التأكيد على المساواة في المنافع الاجتماعية بنسبة99\%؛ التأكيد على المساواة أمام القضاء بنسبة6.2\%، التأكيد على المساواة في القانون والدستور بنسبة\%3.7\%، التأكيد على المساواة في الوظائف العامة بنسبة.2.4\%. - تتوعت الأساليب الصحفية المتبعة في عرض قضايا المواطنة في صحف الدراسة وتمنلت في ؛ الإخبار بنسبة 48.6\%، التتاقتية : بنسبة 14.5\%. والنقد والتقويم بنسبة 13.2\%، الاقتراحات والحلول بنسبة611\% ، 1المقال بنسبة 6.4\%، التحقيق الصحفي بنسبة5.6\% وارتقع استخدامه في جريدة الوطن بنسبة 8.8\%، ويساعد التحقيق على معرفة وجهات النظر الدختلفة حول قضية أو أكثر من قضايا المواطنة. - تتوعت مصادر تغطية قضايا المواطنة في صحف الدراسة، ما بين؛ الصحف المحلية والأجنبية بنسبة 18.7\%، المندوب الصحفي بنسبة 15\%، المراسل بنسبة 13.7\% ، الكتاب المصاحفون بنسبة 13.6\% ، الانترنت بنسبة12\%، وكالات الأنباء العالمية بنسبة 10.8\%، وكالات الأنباء الإقليمية بنسبة 7.3\%،

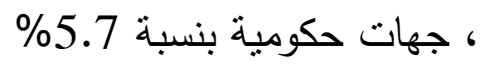
- فيما يتعلق بموقع نشـر قضـايا المواطنة فقد استحوذت الصفحات المتخصصـة على 81.3\% من قضايا المواطنة ، 18.7\% في الصفحة الأولى . 
بناء على نتائج الدراسة التحليلية، يوصي البحث بما يلي : زيادة الاهتمام بقضايا المواطنة ، وتخصيص مساحات أوسع لها.

زيادة الاهتمام بتتوع قضايا المواطنة مثل ؛ إبراز أهمية التاريخ الوطني، التأكيد على الخصوصية

النقافية دون تعصب أو انغلاق، الفخر والاعتزاز بالوطن، الاهتمام بقضايا المساواة.

زيادة الاهتمام بالجهات الحكومية والتقارير الرسمية كمدر لقضايا المواطنة في صحف الدراسة.

زيادة الاهتمام بالمقالات والتحقيقات الصحفية التي تساعد على إبراز قضايا المواطنة.

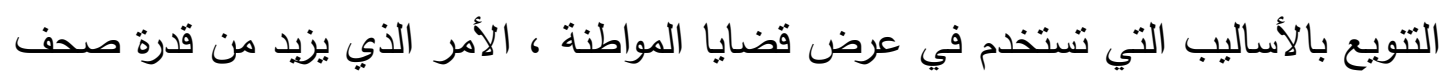

الدراسة في الإقناع والثأثثر ، ويساعد على الوصول إلى الأهداف المطلوبة، بأقصر وقت ، وأقل

جهد.

ضرورة الاهتمام بالمصادر الإعلامية الداخلية الخاصة، وذلك بتعيين مراسلين ، لأن هذا النوع

من المصادر هو الذي يميز صحيفة عن أخرى، إضافة إلى الاهتمام بتوثيق الأخبار والموضوعات

، ونسبتها إلى مصادرها، الأمر الذي يزيد من ثقة الجمهور بها.

استخدام كافة الفنون الصحفية في عرض قضايا المواطنة ، وخاصة الحديث والتحقيق الصحفي،

نظراً لقدرتهما على شرحها ، وتفسيرها ومناقتشها ، وتقديم الحلول لها ، وهو ما يتطلب إعداد كادر

صحفي قادر على استخدامهما بفاعلية ، ويشبع رغبة الجمهور .

اسـتخدام وسـائل الإبراز المختلفة وخاصـة العناوين الفرعية ،والصـور والرسـوم نظراً لما لها من قدرة

على جذب الجمهور إليها ، إضافة إلى ضرورة التوازن في إبراز قضايا المواطنة. المصادر والمراجع

أولاً : المراجع العربية : (2) 
- أحمد محمد حسن ربايعة(2019) دور الإعلام في تعزيز القيم الوطنية. رؤية استراتيجية في ضوء التصور الإسلامي، الجامعة الأردنية، دراسات- العلوم الإنسانية والاجتماعية، مج46، ص ص ص 19-49.

- الدويلة ،أمل بدر (2015) قيم المواطنة لدى طلبة جامعة الكويت وعلاقتها ببعض المتغيرات ، المجلة التربوية - الكويت، مج29, ع114.

- العصفور ،عثمان أحمد (2009) الثعور بالمواطنة والعوامل التي تساعد على زيادتها في المجتمع الكويتي، دراسة استطلاعية. مكتب الإنماء الاجتماعي: الكويت. - الغامدى، عبد الرحمن بن على (1430) قيم المواطنة لدى طلاب المرحلة الثانوية بمكة المكرمة وعلاقتها بالأمن الفكري من منظور تربوي إسلامي، رسالة ماجسنير غير منشورة، كلية التربية جامعة أم القرى.

- أماني محمد طه وفاروق جعفر عبد الحكيم(2013) تربية المواطنة بين النظرية والتطبيق. القاهرة: مكتبة

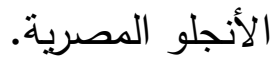

- حسيبة ناريمان بلعباس(2018) واقع قيم المواطنة في الصحافة الجزائرية دراسة تحليلية للعمود الصحفي: نقطة نظام بصحيفة الخبر أنموذجا، جامعة عبدالحميد بن باديس - كلية العلوم الاجتماعية، مجلة الحوار التقافي، مج8، ع1، ص ص 95-118.

- حنان سيد محمد حامد (2012) ثقافة المواطنة لاى طلاب التعليم الثانوي الفني بث حالة ، رسالة دكتوراه غير منشورة ، معهد الدراسات التربوية ، جامعة القاهرة. 
- حنان مراد وجنان مالكي ( 2011) أثر الانفتاح الثقافي على مفهوم المواطنة لدى شباب الجزائر بجامعه محمد خيضر بسكرة، مجلة العلوم الإنسانية والاجتماعية، جامعه محمد خيضر بسكرة، الجزائر، ع3.

- رويد أحمد طلب أحمد محمد(2014) معالجة الخطاب الصحفي لقيم المواطنة فى المجتمع المصري : دراسة تحليلية لصحيفتى الوفد - الحرية والعدالة عام 2011 ، جامعة عين شمس - كلية البنات للآداب والعلوم والتربية، مجلة البحث العلمي في الآداب، عـ15، ج1، ص ص 369-407.

- سمير حسين(2006) دراسات في مناهج البحث العلمي :بحوث الإعلام، القاهرة :عالم الكتاب.

- سميرة لغويل(2019) قيم المواطنة في المجتمع الجزائري : دراسة تحليلية ، جامعة بغداد، كلية التربية،

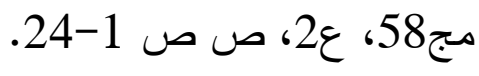
- عبد العزيز خلف خليل الجبوري(2019) قيم المواطنة في الصحافة الإماراتية: دراسة تحليلية لمقالات كتاب الرأي في صحيفة الاتحاد الإماراتية، مجلة العربي للاراسات الإعلادية، المركز العربي للأبحاث والدراسات الإعلامية، ع1 إبريل، ص ص 169-185.

- غربية، سمراء(2016) دور الإعلام في ظل تحديات العولمة في تأكيد قيم المواطنة في المجتمع الجزائري، جامعة محمد خيضر بسكرة، مجلة العلوم الانسانية ، ع44.

- ليلى حسين السيد و حسن عماد مكاوي(2004) الاتصال ونظرياته المعاصرة ، القاهرة: الدار المصرية اللبنانية. 
- محمد عبد البديع السيد(2016) دور وسائل الإعلام الجديدة في دعم المواطنة الرقمية لدى طلاب الجامعة، مجلة بحوث العلاقات العامة الثرق الأوسط، ع12، سبتمبر .

- نورة عمر العتيبي(2018) قيم المواطنة لدى طلبة جامعة الملك سعود ، الجمعية المصرية للأخصائيين الاجتماعيين، مجلة الخدمة الاجتماعية، ع60، ج2، ص ص 101-121.

- وسام صقر (2010) الثقافة السياسية وانعكاسها على مفهوم المواطنة لدى الثباب الجامعي في قطاع غزة -2005-2009، رسالة ماجستير غير منشورة ، كلية الاقتصاد والعلوم الإدارية ، جامعة الأزهر ، غزة .

- يعقوب يوسف الكندري(2011) قيم الانتماء الوطني و المواطنة : دراسة لعينة من الثباب في المجتمع الكويتي ، جامعة الكويت، مجلة دراسات الخليج والجزيرة العربية،عائ142، ص ص 17-74.

ثانياً : المراجع الأجنبية :

- Entman, R.M. (1991) Framing US Coverage of International News: contrasts in narratives of the KAL and Iran air incidents, Journal of communication, vol.41, no.4. - Magick Hanray, (2007) University students in the impact of the rights and duties of citizenship education and their roles in society and the democratic United States of America.

- Sharon Hartin Iorio, and Susan Schultz Huxman, "Media Coverage of Political Issues and the Framing of Personal Concerns," Journal of Communication 46, no. 4 (1996): 98-99. [database on-line]; available from Questia, 
http://www.questia.com/PM.qst?a=o\&d=96517768; Internet; accessed 4 October 2007.

- Wolfsfeld, G.(1991), Media , protest, and political Violence: A transactional Analysis, Journal of Monographs , No. 127, June.

- ynn Dobson: Citizenship in Reader's guide to the social science. Fitzroy Dearborn Publish. Landon. Vol 1.2002.pp(197-198).

Frameworks For Handling Citizenship Issues In Kuwaiti Newspapers. A Comparative Analytical Study

Prepared By

Nayef Mohammed Hamyan Al-Arada

Supervised By

Prof. Dr.

Suzan Al-Qeleny

Professor of mass

communication - Dean of

college of Literature previously -

Ain Shams University
Dr.

Asmaa Abd El Shafie

Teacher of public relations and mass

communication

College of Literature - mass

communication department

Ain shams university 


\section{Abstract}

The study problem was determined in answering a whose content is "What are the frameworks for Kuwaiti printed newspapers to deal with citizenship issues?" The study aimed to identify the frameworks for Kuwaiti printed newspapers dealing with citizenship issues.

The media framework analysis theory was relied upon to understand and comprehend the framework in which Kuwaiti newspapers discuss citizenship issues by analyzing the content of these issues, and clarifying how Kuwaiti newspapers deal with citizenship values.

The study belongs to the descriptive and analytical studies in the field of media, and the study relied on two approaches to answer its questions, namely: the media survey method and the comparative approach. The analytical study community focuses on journalistic contents that deal with citizenship issues. The study sample was represented in (Al-Watan newspaper - Al-Nahar Kuwaiti newspaper - Kuwaiti Al-Rai newspaper)

The results of the study confirmed:

- Kuwaiti newspapers' interest in citizenship issues, at the forefront of which are; Upholding the state's sovereignty internally and externally, affirming the rights and duties of the individual and society, affirming privacy and self-identity, affirming the values of tolerance, affirming equality.

The journalistic methods used in presenting citizenship issues in study newspapers varied, and they were represented in: Informing, discussion. And criticism and evaluation, suggestions and solutions, the article, the press investigation. - The sources of covering citizenship issues in the study newspapers varied between; Domestic and foreign newspapers, press representatives, correspondents, writers, writers, writers, Internet, and news agencies. 
العتى الئالهيه - اليزو الأول(2021)

cos.alt

"العلوم/لاجتماعيةوالإسانية"

The study recommended the following:

1- Increasing interest in the diversity of citizenship issues such as:

Highlighting the importance of national history, emphasizing cultural specificity without fanaticism or isolation, and pride in the homeland 2- Increasing interest in official reports as a source for citizenship issues in study newspapers.

3-Increasing interest in articles and journalistic investigations that help highlight citizenship issues.

Keywords: Press treatment - Citizenship question. 